\title{
Talking with Families about Things that are Hard for Them to Hear
}

\author{
Stephen Robinson \\ Speech-Language Therapist, Ministry of Education, Special Education (GSE), Rotorua.
}

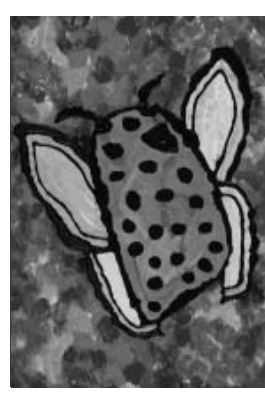

\section{ABSTRACT}

This article is based on the author's personal experience of an uncomfortable discussion with a family. Issues are explored around the difficulty in anticipating how a young child with a learning delay will respond to speech-language therapy and how the practitioner will give accurate information. Two key journal articles on giving bad news are summarised.

\section{Practice paper KEYWORDS \\ Communication skills, interpersonal communication, family involvement, parent school relationship.}

His mother came over to me and said, "Hello". His grandmother was with her, too. His mother explained that they were concerned about his progress with language and speech. He was still very hard to understand, and they wanted to know what I had been doing in my sessions with him. That morning in the early childhood centre, my thoughts were jumbled as I started to speak, and I stuttered at first. There was so much they needed to understand about typical development before I could start to explain why I had not been 'teaching' him for the previous six months, and it took me a few moments to collect my thoughts and find a way to do this.

His mother also wanted to know when the centre was going to start teaching him. He had recently turned four, and she was anxious because he would be going to school in a year. "Last year, he just played", she said.

They listened politely as I tried to form a coherent explanation. I did explain that young children learn through play, and I tried to explain that 'play' was the right thing for a three-yearold to do. I also said that the play activities at the centre were designed to encourage development and that the very able staff were supporting him with his learning in very appropriate ways. I am sure I said all this, but I am not sure they heard it.

They were right: he was hard to understand, with many sound substitutions, and what we could understand was very simple language for a child his age. There were seldom more than three words in a sentence and few grammatical markers in his speech. He had had ear infections but there was nothing else in his background to explain the delay.

On top of this, he was resistant to speech work. Most children I work with quickly become comfortable with desk work sitting at a table and doing fairly formal speech-language therapy - and many of them look forward to our sessions: beating me at Memories, saying their practice words and getting a small sticker at the end.
Not him, though. He always played outside and it was next to impossible to coax him to come in like the other children I saw at that centre. I tried different approaches: asking him, telling him, and taking him by the hand and leading him. When I tried persuasion, he would look up from the sand he was digging in and say, "When me bigger".

The funny thing was, he was right. He had a lot of development to go through and he was not going to do it faster just because his mother, his grandmother and I thought he should.

After my long and nervous explanations to his mother and grandmother that day, I stopped pressing him for several months but kept in touch. When I visited the centre I would make sure I spent a few minutes with him, perhaps crouching down when he was busy in the sand, and commenting on what he was doing. The staff at the centre continued to look for opportunities to feed in language, too. When I saw his mother, I made encouraging comments about what I had seen recently.

The next term, when he was nearly four and a half, he was ready to come inside and play Memories with me or talk about vocabulary pictures for a few minutes, but not both. Pretty soon I was able to do some formal testing with him and finally I was able to write a programme. By then, he was prepared to have a go at the practice words and get a small sticker at the end. Memories was a challenge for him at first, and he knew a few diverting behaviours when the words were difficult to say. He might drop his hat on the ground then want to pick it up, or slip off the adult-sized chair and disappear under the desk.

He is nearly five and a half now, and everyone can understand him most of the time. He still says "me" for "I" occasionally, and I still see him for his speech sounds. He has made a good transition to school, and he is happy to come to a side room and do his 'special talking' now, although he still comes across as immature in his social skills.

It can be very hard, at the beginning, to tell those children who will get the spark and make quick progress, and those who will take longer, and make progress in small slow steps. It often takes time, months, perhaps, to try a few approaches and see if they work. Then, having spent all that time with a child it can be hard to step back and say, "they are not ready yet". I find it hard to say it to myself, and even harder to explain it to others. 
I am getting better at it, telling parents their child is a 'slower learner'. I seldom use that phrase, though. I say they are learning and developing, but at their own pace. I can usually back this up with examples. I try to explain the underlying theory: development is accretive, each step building on the previous and none can be missed, but this can go over their heads. I have been thinking about this for a while. I used to get defensive, emphasising the positive and not wanting to admit the difficulties. I even find it hard to write the negatives'. These days I can agree, and empathise, if a parent feels their child is 'behind' compared to most children.

While I was thinking about this child, and the difficult discussion I had with his mother and grandmother, I decided to see if there was any literature on giving bad news that would help me out. I searched the Internet, and asked the staff at the GSE library to have a look, too. I found a couple of business articles, such as how to tell an employee they missed out on a promotion, and the GSE library found a dozen or so for doctors, for example, discussing the delivery of a diagnosis of cystic fibrosis.

Professionals in education rarely have to give news with the implications that medical professionals do, but we do talk with families about things that are hard for them to hear. Perhaps the child has not made the progress we had hoped for, or we feel a situation is severe and calls for strong measures. Perhaps we are the ones to confirm their fears or put a name to their concerns. Sometimes they want a label for what is wrong with their child. Sometimes that is the last thing they want. Either way, the child's education opportunities are likely to be reduced or limited in some way.

I thought back, trying to remember any training on this topic I had, or courses colleagues had reported back on. When I trained as a Speech-Language Therapist, I remember students role-playing discussions with family members, including giving the results of our assessments and explaining what it meant for the person. I also know that my colleagues working with challenging behaviour regularly have difficult discussions with schools and families, so I was surprised that the literature search had not found anything other than medical journal articles. Reading the articles we had found, I saw that while there is good advice and theory that seems sound, there are broad gaps in the research, especially around what works best for families. Most of the research looked at what works best for doctors.

However, there were two articles that were often referenced by the others, and are well worth reading. They are both accessible, thoughtful and helpful. One is a review of the medical literature on breaking bad news (Ptacek \& Eberhardt, 1996), and the other offers a protocol for delivering bad news (Baile, Buckman, Lenzi, Glober, Beale, \& Kudelka, 2000). It is worth summarising the main points of each, and considering how they can be applied to our education setting.
Ptacek and Eberhardt (1996) read 67 articles that had been published in medical journals since 1985 . They summarised a number of the issues and the advice most often given.

1. Meet in a quiet, comfortable and private place.

2. Arrange a convenient time, so the discussion is not rushed and there will be no interruptions.

3. Meet in person - make eye contact, sit close to the person and avoid physical barriers such as a desk.

4. Give the person the option of having a support person present.

5. Prepare what you will say, and give them some warning that it may be unwelcome news.

6. Convey some measure of hope.

7. Acknowledge and explore their reaction, and allow for any expression of emotions.

8. Allow for questions.

9. Show warmth, caring, empathy and respect.

10. Be careful around your choice of words to ensure that they will understand you, avoid euphemisms or technical jargon. Euphemisms can make bad news sound good, and be confusing.

11. Give the news at the person's pace, allowing them to dictate what they are told and when.

12. Summarise the discussion at the end - either verbally or in writing.

Baile et al. (2000) also acknowledged the gaps in empirical research around giving bad news, and explored the issues that had been identified in previous literature. Their protocol, 'SPIKES, 'is difficult to summarise without losing important information, but the letters stand for six steps in giving bad news.

1. Set up the interview.

2. Access the patient's Perception (finding out what they know already will help shape how the news is delivered).

3. Obtain the patient's Invitation (finding out how much they want to know, and how they want to be told).

4. Give Knowledge and information to the patient.

5. Address the patient's Emotions with empathic responses.

6. Strategy (what is going to be done about it) and Summary.

Their discussion around these points echo much of what Ptacek and Eberhardt (1996) found, and on the face of it, both articles can be adapted to educational situations to provide us with useful guidance. It is important not to fall into the same trap - working from what seems sensible but without research into the practical application of such a framework. 
It is vital to have research focused on education in New Zealand: evidence to inform our practice. For example, there must be some cultural issues to be taken into account, and other differences, too. Research could investigate the experiences of education professionals in New Zealand, the range of training they had received (taking the best from each, perhaps) or any support they would like to have. Family perceptions could be canvassed. A more determined literature search might find articles with greater relevance to special education.

Looking back at the vignette I presented at the beginning of the article, and thinking about the strategies I have outlined, that situation would still have been difficult for me. To begin with, I did not have time to prepare the information or the setting. Perhaps I needed to talk to the boy's family more, or at least check that they understood the approach I was taking and why. I could have been more proactive and if I had followed the advice of these two articles, I might have been more successful in keeping the family informed. This might have prevented them needing to approach me in that way, which was uncomfortable for all of us.

\section{REFERENCES}

Baile, W. F., Buckman, R., Lenzi, R., Glober, G., Beale, E. A., \& Kudelka, P. (2000). SPIKES-A six-step protocol for delivering bad news: Application to the patient with cancer. The Oncologist, 5, 302-311.

Ptacek, J. T., \& Eberhardt, T. L. (1996). Breaking bad news: A review of the literature. Journal of the American Medical Association, 276, 496-502.

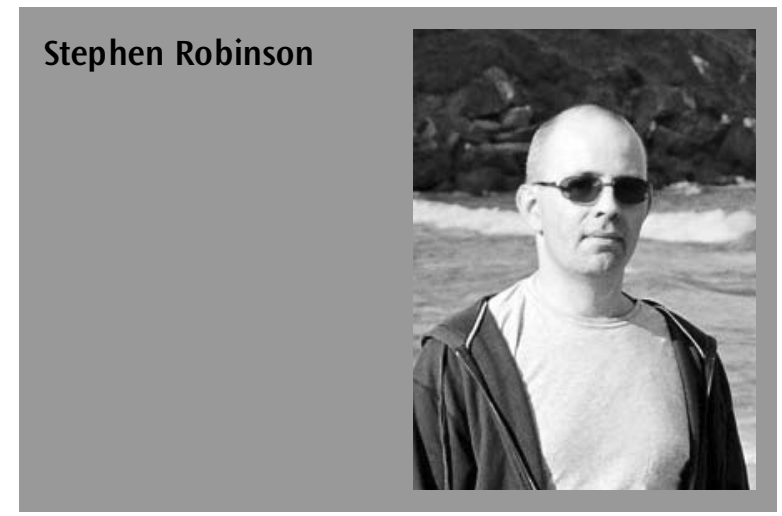

\section{AUTHOR PROFILE}

Stephen Robinson is a Speech-Language Therapist who has worked in Rotorua and in the field of special education for the past 10 years.

\section{Email}

stephen.robinson@minedu.govt.nz 